Toshiaki Nishikawa MD, Yukinobu Anzai MD, Akiyoshi Namiki MD

\title{
Asystole during spinal anaesthesia after change from Trendelenburg to horizontal position
}

Wepresent a case in which progressive bradycardia and sudden cardiac arrest developed in a 26-year-old healthy woman with an ovarian cyst during spinal anaesthesia, immediately after the patient was moved from the $15^{\circ}$ Trendelenburg to the supine horizontal position. We postulate that a decrease in venous return was the main cause of the cardiac arrest. It should be stressed again that close monitoring during spinal anaesthesia is essential when the patient is subjected to postural changes.

Sinus bradycardia after spinal anaesthesia is frequently encountered in ordinary clinical settings. ${ }^{1-3}$ However, the incidence of cardiac arrest during spinal anaesthesia is extremely low, ${ }^{4}$ Bradycardia during spinal anaesthesia has been ascribed to either an interruption of the cardiac accelerator fibres or a decrease in venous return, or to both. ${ }^{1-3}$ Recently, it has been suggested that cardiac yagal tone is enhanced mainly through a decrease in the venous return during lumbar epidural blockade ${ }^{5}$ Therefore, venous return is of importance in the regulation of heart rate, particularly during regional anaesthesia. In this report, we present a case in which progressive bradycardia and asystole developed during spinal anaesthesia, immediately after the patient was moved from the Trendelenburg to the supine horizontal position.

\section{Case report}

A 26 -year-old, $46 \mathrm{~kg}, 156 \mathrm{~cm}$ woman was scheduled to undergo an oophorectomy for an ovarian cyst, under

\section{Key words}

ANAESTHESIA, REGIONAL: spinal; COMPLICATIONS: cardiac arrest; POSITION: Trendelenburg, supine horizontal.

From the Institute of Clinical Medicine, University of Tsukuba, Tsukuba-City, Ibaraki, Japan, and the Department of Anesthesiology, Sapporo Medical College and Hospital, Sapporo, Japan.

Address correspondence to: Dr. Nishikawa, Institute of Clinical Medicine, University of Tsukuba, Tsukuba-City, Itharaki 305, Japan. spinal anaesthesia. She had no specific findings in her medical history except that she had suffered from lightheadedness several times and syncope once in the past. However, the cause of the episodic faintness had not been defined. A preoperative electrocardiogram revealed a sinus arrhythmia with a rate of 53 beats $\cdot \mathrm{min}^{-1}$. Prcoperative haemoglobin, haematocrit and blood sugar were 11.0 $\mathrm{g} \cdot \mathrm{dl}^{-1}, 34.4$ per cent and $173 \mathrm{mg} \cdot \mathrm{dl}^{-1}$, respectively. Positive ketone bodies were found on urinalysis, but other preoperative laboratory data were within normal limits.

The patient had fasted preoperatively for six hours. Premedication consisted of hydroxyzine $100 \mathrm{mg}$ IM one hour before the start of anaesthesia. On arrival in the Operating Room, her blood pressure was $116 / 67 \mathrm{mmHg}$, heart rate 63 beats $\cdot \mathrm{min}^{-1}$, and respiratory rate 14 breaths $\cdot \mathrm{min}^{-1}$. She was well sedated, but lucid. A 16-gauge venous cannula was placed for administration of lactated Ringer's solution. Following sterile preparation of the skin, a 25-gauge spinal needle was inserted in the $\mathrm{L}_{3-4}$ intervertebral space while the patient was lying in the right lateral position. After a free flow of clear cerebrospinal fluid was confirmed, $2.4 \mathrm{ml}$ of solution of 0.5 per cent tetracaine in ten per cent dextrose to which $3.7 \mathrm{mg}$ of phenylephrine had been added, was injected over 5 sec. No adverse reaction was observed during the subarachnoid injection. The patient was immediately placed in the supine horizontal position. At that time, her blood pressure and heart rate were $90 / 34 \mathrm{mmHg}$ and 53 beats $\cdot \min ^{-1}$. Because sensory blockade was found only below $\mathrm{T}_{10}$, approximately three minutes after the tetracaine injection, the head of the operating table was lowered by about 15 degrees in order to extend the analgesia. During this period in the Trendelenburg position, the blood pressure and heart rate showed little change. The patient did not complain of any nausea or discomfort. About $500 \mathrm{ml}$ of lactated Ringer's solution had been infused up to this time. Because an upper level of analgesia to $T_{5}$ was obtained five minutes after the induction of anaesthesia, the table was returned to the previous horizontal position. Shortly thereafter, the heart rate progressively decreased from 54 to 30 beats $\cdot \mathrm{min}^{-1}$, then standstill of the heart occurred. The patient's 
eyeballs rolled upward and consciousness was lost. Closed cardiac massage was performed while the lungs were ventilated with pure oxygen by mask. Atropine 0.5 $\mathrm{mg}$ and ephedrine $10 \mathrm{mg}$ were given IV immediately. After about 30 seconds the heart regained a normal sinus rhythm and spontaneous respiration also appeared. The blood pressure increased to $144 / 76 \mathrm{mmHg}$, and the heart rate increased to 93 beats $\min ^{-1}$, one minute after the initiation of resuscitation. The patient regained consciousness, became well oriented, and responded to verbal commands. The upper level of analgesia to pinprick was at $T_{5}$. The remaining one-hour anaesthetic course was uneventful.

The removed ovarian cyst weighed about $220 \mathrm{~g}$. The patient was discharged two weeks after the operation without any sequelae. Detailed cardiovascular tests were carried out one month after the operation. Postural changes in blood pressure were not observed. Additionally, no abnormality was proved by means of a Holter electrocardiogram, an echocardiogram, and a Master's excercise test. There was no evidence of autonomic neuropathy in the analysis of beat-to-beat variations in the heart rate when the patient breathed deeply or was tilted head-up. A mild glucose intolerance was ascertained by a glucose tolerance test, and an increased free fatty acid was noted (1260 $\mu \mathrm{Eq} \cdot \mathrm{L}^{-1}$; normal range $\left.170-590\right)$. The patient was diagnosed as having borderline diabetes mellitus, requiring no special treatment.

\section{Discussion}

Although the cause of cardiac arrest in this patient can not be defined conclusively, it is reasonable to assume that moving the patient from the Trendelenburg to the supine horizontal position contributed mainly to this circulatory catastrophe.

Bradycardia as one of the characteristic features during spinal anaesthesia has been attributed to either preganglionic block of the cardiac accelerator fibres or a decrease in the venous return to the heart, or to both. ${ }^{1-3}$ It is presumed that the upper level of sensory blockade at $T_{\mathfrak{s}}$ in this case may indicate an almost complete interruption of the cardiac efferent sympathetic nerves, according to Chamberlain and Chamberlain's recent demonstration that the mean sympathetic-sensory differential with tetracaine anaesthesia is more than six segments. ${ }^{6}$ In addition, Baron et al. ${ }^{5}$ observed a resetting of the baroreflex due to decreased venous retum after lumbar epidural anaesthesia in humans. It has also been shown in elderly men that the heart rate and catecholamine responses to the hypotension induced by a 30 -degree head-up tilt are impaired. ${ }^{7}$ These findings may indicate an inadequate compensatory mechanism of circulation after regional anaesthesia. The rhythm of the heart can be thus affected by venous return ${ }^{1,2}$ which is in turn influenced by postural changes. Accordingly, it seems likely that this progressive bradycardia and asystole could be induced chiefly by an abrupt decrease in venous return, secondary to the postura] change from the Trendelenburg to the horizontal position.

Although the size of the removed ovarian cyst in our case appeared too small to obstruct the inferior vena cava, large intraabdominal masses such as a gravid uterus and pelvic tumours can induce the "supine hypotensive syndrome," secondary to a decrease in venous return, particularly after regional blockade. ${ }^{8,9}$ Likewise, an inadvertent upward extension of the motor blockade leading to respiratory insufficiency can be excluded as the cause of the cardiac arrest, since adequate spontaneous respiration and the $T_{5}$ level of analgesia were confirmed both before and after the resuscitation. It is clear that the patient should have been immediately placed in the head-down position, because venous return seems to play a critical role in the regulation of heart rate, especially in the presence of sympathetic denervation.

It has been shown that respiratory sinus arrhythmia reflects an adaptation of the cardiac frequency to the respiratory fluctuations of the venous return, ${ }^{10}$ and that parasympathetic influences predominate in the regulation of resting heart rate. ${ }^{11}$ Therefore, the patient's preoperative electrocardiogram showing sinus arrhythmia and bradycardia likely indicates that our patient might already have been in a vagal dominant state and her heart rate might be extremely vulnerable to changes in venous return. The history of episodic faintness may suggest a vagus-mediated syncope, through either pronounced bradycardia or transient asystole.

There are many reports that diabetic neuropathy affects the heart, resulting in a predominantly vagal denervation. ${ }^{12,13}$ As a result, tachycardia and little beat-to beat variation ( $R R$ interval) in the heart rate become manifest in the symptomatic or even the asymptomatic diabetic. However, our patient exhibited no abnormal finding at the time of monitoring of the RR interval, when she breathed deeply or was tilted head-up. The neuropathy due to diabetes mellitus should preferentially counteract the vagal-mediated circulatory responses, thereby making this unlikely as the cause of the cardiac arrest. Finally, the history of episodic light-headedness could be related to idiopathic hypertrophic subaortic stenosis, ${ }^{14}$ which, however, was not evident on a postoperative echocardiogram.

In summary, we described a case in which a sudden cardiac arrest occurred immediately after the patient was moved from the 15-degree head-down to the horizontal position during spinal anaesthesia. A decrease in venous return was presumably the main causative factor for this event. It must be stressed again that close monitoring during spinal anaesthesia is essential, particularly when 
patients with evidence of enhanced vagal tone are subjected to postural changes.

\section{References}

1 Greene NM. Preganglionic sympathetic blockade in man: a study of spinal anesthesia. Acta Anaesthesiol Scand 1981; 25: 463-9.

2 Wetstone $D L$, Wong $K C$. Sinus bradycardia and asystole during spinal anaesthesia. Anesthesiology 1974; 41: $87-9$.

3 Sancetta $S M, L y n n R B$, Simeone FA, Scott RW. Studies of hemodyramic changes in humans following induction of low and high spinal anesthesia I. General considerations of the problem. The changes in cardiac output, brachial arterial pressure, peripheral and pulmonary oxygen contents and peripheral blood flows induced by spinal anesthesia in humans not undergoing surgery. Circulation 1952; 6: 559-71.

4 Moore DC, Bridenbaugh LD, Bagdi PA, Bridenbaugh PO, Stander $H$. The present status of spinal (subarachnoid) and epidural (peridural) block: a comparison of the two technics. Anesth Analg 1968; 47:40-9.

5 Baron J-F, Decaux-Jacolot A, Edoward A, Berdeaux A, Samii $K$. Influence of venous return on baroreflex control of heart rate during lumbar epidural anesthesia in humans. Anesthesiology 1986; 64: 188-93.

6 Chamberiain DP, Chamberlain BDL. Changes in the skin temperature of the trunk and their relationship to sympathetic blockade during spinal anesthesia. Anesthesiology 1986; 65: 139-43.

7 Ecoffey $C$, Edouard A, Pruszczynski W, Taly E, Samii $K$. Effects of epidural anesthesia on catecholamines, renin activity, and vasopressin changes induced by tilt in elderly men. Anesthesiology 1985; 62: 294-7.

8 Bieniare J, Crotogini JJ, Curuchet $E$ et al. Aortocaval compression by the uterus in late human pregnancy II. An arteriographic study. Am J Obstet Gynecol 1968; 100 : 203-17.

9 Schroeder $G M$, Jebson $P J$. The supine hypotension syildrome in a young boy. Anesthesiology 1986; 64: $377-8$.

10 Melcher A. Respiratory sinus arhythmia in man: a study in heart rate regulating mechanisms. Acta Physiol Scand 1976; 435(suppl): 1-31

11 O'Rourke GW, Green NM. Autonomic blockade and the resting heart rate. Am Heart J 1970; 80: 469-74.

12 Wheeler $T$, Watkins $P J$. Cardiac denervation in diabetes. Br Med J 1973; 4: 584-6

13 Murray A, Ewing DJ, Campbell $W W$. Neilson JMM, Clarke $B F$. RR interval variations in young male diabetics. $B T$ Heart J 1975; 37; 882-5.

14 Braunwald E. Heart disease. A textbook of cardiovascular medicine. Vol 2. Philadelphia: W.B. Saunders Company. pp. $1447-60,1980$.

\section{Résumé}

On présente le cas d' une bradycardie progressive et d'un arrêt cardiaque lors d' une anesthésie rachidienne chez une paiente agé de 26 ans présentamt un kyste ovarien survenant immédiatememt après changement de position d' un Trendelenbourg de $15^{\circ}$ d une pasition horizontale. On pense que la diminution $d u$ retour veineux est la cause principate de l'arrêt cardiaque. On doil insister sur le fait qu' une surveillance étroite est nécessaire lors d'une rachi anesthésie quand le patient est asujetti à des changements de position. 